\title{
Effect of catalyst on tail gas during reduction of vanadium- titanium magnetite carbon-containing pellet
}

\author{
Bo Wang ${ }^{1}$, Xueyong Ding ${ }^{1 *}$, Xiaofei Zhang ${ }^{1}$, Tianhua $\mathrm{Ju}^{1}$ and Shigang $\mathrm{Li}^{2}$ \\ ${ }^{1}$ Northeastern University, School of Metallurgy, 110819, Shenyang, China \\ ${ }^{2}$ Beijing Peking University Pioneer Technology Co., Ltd, 100080, Beijing, China
}

\begin{abstract}
Catalyst can enhance the reduction effect and promote the reduction of vanadium titanomagnetite. In this paper, the carbon-containing pellets of vanadium titanomagnetite were prepared by using highly volatile coal as the reducing agent under the background of a novel process of pre-reduction in the rotary kiln. The effects of $\mathrm{CaO}, \mathrm{CaCO}_{3}, \mathrm{~B}_{2} \mathrm{O}_{3}$ and borax $\left(\mathrm{Na}_{2} \mathrm{~B}_{4} \mathrm{O}_{7} \cdot 10 \mathrm{H}_{2} \mathrm{O}\right)$ on the tail gas characteristics of carboncontaining pellets in the prereduction process were studied by using a simulated rotary kiln and flue gas analyzer. The results showed that the enhanced reduction effect of boron catalysts was slightly stronger than that of calcium catalysts, among which $\mathrm{CaO}$ catalyzed the least and borax the best. With the increase of metallization rate, the $\mathrm{CO}$ utilization in the tail gas is generally reduced, while when using $\mathrm{CaCO}_{3}$ as the catalyst, the $\mathrm{CO}$ utilization is significantly increased. Due to different reduction mechanism, the boron catalysts have little effect on the tail gas, and the calcium catalysts have a great effect on the tail gas. Based on the experimental results and the characteristics of the tail gas from the reduction process, we put forward the idea of using $\mathrm{CaCO}_{3}$ as the best catalyst and using $\mathrm{CaO}$ to absorb $\mathrm{CO}_{2}$ in the tail gas to form $\mathrm{CaCO}_{3}$.
\end{abstract}

\section{Introduction}

The iron and steel industry plays a very important role in mitigating global climate change[1]. As the emission requirements for steel companies increased, exploring new technologies to reduce carbon dioxide emissions is of great significance[2]. Non-blast furnace ironmaking technology has been developed in recent decades by eliminates the severely polluting and high energy consumption processes as coking and sintering in the traditional blast furnace route[3]. The Central Iron and Steel Research Institute creatively put forward a novel ironmaking process of pre-reduction in rotary kiln and total oxygen melting pool, aiming to completely get rid of the dependence on coke and sintering[4-6].

As a typical type of complex iron ore with the coexistence of titanium and vanadium, vanadium-titanium magnetite (VTM) is widely distributed in China. At present, VTM concentrates is mainly make pig iron by smelting and separating in blast furnace[7, 8], but this method has many disadvantages that limit its development. Carbon-containing pellet technology is a low-carbon technology that has attracted much attention and is widely used in the field of coal-based ironmaking process[9]. ElTawil[10] has investigated the possibility of the effective use of woody biomass in carbon-iron oxide composites. And found that increasing biomass charcoal can increase the porosity of the pellets and improve the mass transfer conditions. Therefore, combining carbon-containing pellet technology with non-blast furnace ironmaking can solve the difficulties faced by blast furnace smelting of vanadium-titanium magnetite to a greater extent.

Catalyst is a substance that can change the reaction rate of a chemical reaction but consumes very little. In order to strengthen the reduction effect of VTM, many scholars have conducted a lot of research on finding the suitable catalyst for vanadium-titanium magnetite[11-14]. These studies mainly focused on the research of the catalyst's reduction effect and the product metallurgical performance, but the impact of the catalyst on the environment and energy utilization rate was not explored. To explore a catalyst that can reduce carbon dioxide emissions and improve energy efficiency, it is significant to study the tail gas's components during the reduction process.

Based on the characteristics of the novel pre-reduction process of a rotary kiln, the reduction effect of four different catalysts was comprehensively evaluated by combining the data of the gas analyzer and the chemical composition analysis of the products. Wishing to provide a 


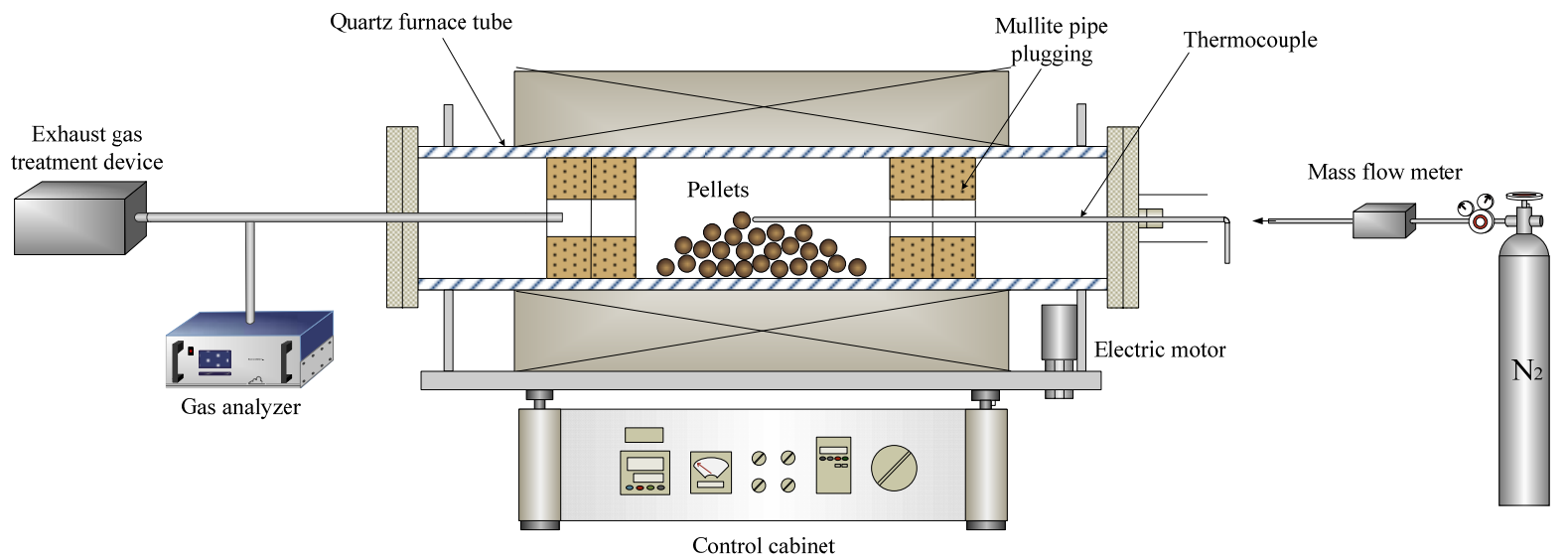

Figure 1. Schematic diagram of laboratory-scale simulation of rotary kiln equipment experiment.

reference for the low-carbon smelting of vanadiumtitanium magnetite.

\section{Materials and Methods}

\subsection{Raw Materials}

This study used the vanadium-titanium magnetite concentrate powder provided by Panzhihua Iron and Steel, and its chemical composition analysis is shown in Table 1. The reducing agent is gas coal provided by a factory in Liaoning province, and the industry analysis and elemental analysis are shown in Table 2. It can be seen from Table 2 that the volatile content of gas coal is very high, reaching $35 \%$, the fixed carbon content is low, and the ash and sulfur content is low. The catalysts are all analytically pure, with a purity of over $98 \%$.

Table 1. The chemical compositions of vanadium-titanium magnetite concentrate (\%).

\begin{tabular}{cccccccc}
\hline $\mathrm{TFe}$ & $\mathrm{FeO}$ & $\mathrm{TiO}_{2}$ & $\mathrm{MgO}$ & $\mathrm{SiO}_{2}$ & $\mathrm{Al}_{2} \mathrm{O}_{3}$ & $\mathrm{CaO}$ & $\mathrm{V}_{2} \mathrm{O}_{5}$ \\
\hline 55.55 & 29.31 & 10.27 & 2.28 & 4.88 & 4.11 & 1.47 & 0.62 \\
\hline
\end{tabular}

Table 2. Proximate and ultimate analysis of gas coal (\%).

\begin{tabular}{ccccccccc}
\hline \multicolumn{4}{c}{ Industry analysis } & \multicolumn{4}{c}{ Elemental analysis } \\
\hline $\mathrm{C}$ & Volatile & Ash & Moisture & $\mathrm{C}$ & $\mathrm{H}$ & $\mathrm{N}$ & $\mathrm{S}$ & $\mathrm{O}$ \\
\hline 56.0 & 35.1 & 4.8 & 3.9 & 73 & 4.9 & 0.9 & 0.8 & 16.4 \\
\hline
\end{tabular}

\subsection{Materials and Methods}

VTM concentrate and gas coal were dried at a constant temperature of $105{ }^{\circ} \mathrm{C}$ and $80{ }^{\circ} \mathrm{C}$ respectively for 500 min. Then, the pelletizing is carried out by disc pelletizer after the VTM powder and coal powder are taken according to $\mathrm{C} / \mathrm{O}=1$ (molar ratio) and a certain amount of catalyst is added. The prepared green balls were dried in the constant temperature drying oven at $110{ }^{\circ} \mathrm{C}$ until the quality was constant. The pellets after weighing out $20 \mathrm{~g}$ and drying are reduced in a laboratory tubular furnace as shown in Figure 1. Before the experiment, the furnace tube was purified by high purity nitrogen, which was introduced into the furnace at a $2 \mathrm{~L} / \mathrm{min}$ flow rate for 20 min, and then the reduction experiment was carried out. During the reduction experiment process, high-purity nitrogen is introduced at $1 \mathrm{~L} / \mathrm{min}$, in order to control the flow direction of the tail gas and prevent external air from flowing back into the furnace tube to interfere with the test results. Meanwhile, it can serve as a reference gas for tail gas component detection to facilitate the calculation of the volume of the main gas component. After the reduction process is over, the pellets will be taken out for relevant analysis after cooled to room temperature. The flue gas analyzer monitors the tail gas in the reaction process in real-time and records the change in the volume fraction of each component. After the volume fraction of $\mathrm{CO}, \mathrm{CO}_{2}$, and $\mathrm{H}_{2}$ all drop to zero, the detection is stopped.

The utilization rate of $\mathrm{CO}$ is often used to judge the quality of energy utilization. The calculation formula is as shown in formula(1):

$$
\eta \mathrm{CO}=\frac{\varphi \mathrm{CO}_{2}}{\varphi \mathrm{CO}_{2}+\varphi \mathrm{CO}}
$$

where $\eta \mathrm{CO}$ is the $\mathrm{CO}$ utilization, $\varphi \mathrm{CO}$ and $\varphi \mathrm{CO}_{2}$ respectively represent the volume fraction of $\mathrm{CO}$ and $\mathrm{CO}_{2}$ in the tail gas.

To obtain the volume of each component of the tail gas, assuming that the main components in the detected tail gas are only $\mathrm{CO}, \mathrm{CO}_{2}$ and $\mathrm{H}_{2}$, ignoring the influence of a small number of other gases. Therefore, it can be assumed that all the gases detected are $\mathrm{N}_{2}$ except $\mathrm{CO}, \mathrm{CO}_{2}$ and $\mathrm{H}_{2}$, and the flow rate of $\mathrm{N}_{2}$ is fixed at $1 \mathrm{~L} / \mathrm{min}$. Thus, the volume of other gases can be calculated from the ratio of $\mathrm{N}_{2}$ to the tail gas component[15]. The specific formulas are as follows:

$$
\begin{aligned}
\mathrm{V}_{\mathrm{CO}} & =\int_{0}^{\mathrm{t}} \frac{\mathrm{d}(\varphi \mathrm{CO})}{\mathrm{d}\left(\varphi_{\mathrm{N}_{2}}\right)} \mathrm{v}_{\mathrm{N}_{2}} \mathrm{dt} \\
\mathrm{V}_{\mathrm{CO}_{2}} & =\int_{0}^{\mathrm{t}} \frac{\mathrm{d}\left(\varphi_{\left.\mathrm{CO}_{2}\right)}\right)}{\mathrm{d}\left(\varphi_{\mathrm{N}_{2}}\right)} \mathrm{vN}_{\mathrm{N}_{2}} \mathrm{dt} \\
\mathrm{V}_{\mathrm{H} 2} & =\int_{0}^{\mathrm{t}} \frac{\mathrm{d}\left(\varphi_{\left.\mathrm{H}_{2}\right)}\right.}{\mathrm{d}\left(\varphi_{\mathrm{N}_{2}}\right)} \mathrm{vN}_{\mathrm{N}_{2}} \mathrm{dt}
\end{aligned}
$$


where, $\mathrm{V}_{\mathrm{CO}}, \mathrm{V}_{\mathrm{CO}_{2}}$, and $\mathrm{V}_{\mathrm{H}_{2}}$ respectively represent the total volume of $\mathrm{CO}$ and $\mathrm{CO}_{2}$ and $\mathrm{H}_{2}$ during the reduction process, and $\varphi \mathrm{CO}, \varphi_{\mathrm{CO}_{2}}, \varphi_{\mathrm{H}_{2}}$ and $\varphi_{\mathrm{N}_{2}}$ represent the volume fraction of the gas component at a certain time during the reduction process. ${ }^{\mathrm{N}_{2}}$ is the flow rate of $\mathrm{N}_{2}$, in this experiment, it is $1 \mathrm{~L} / \mathrm{min}$.

The metallization rate of the pellet after the reaction was defined as the ratio of the content of metallic iron to the content of total iron in the pellet, which can be calculated as follows:

$$
\mathrm{M}=\frac{\omega(\mathrm{MFe})}{\omega(\mathrm{TFe})} \times 100 \%
$$

where $\mathrm{M}$ is the metallization rate, $\mathrm{MFe}$ and $\mathrm{TFe}$ are the metallic iron content and total iron content in the reduced pellets, respectively.

\section{Results and Discussion}

\subsection{Effect of different catalysts on metallization rate of vanadium titanomagnetite carbon pellets}

Figure 2 shows the influence of different catalysts and their addition amount on the metallization rate of pellets. (the number in brackets is the amount of catalyst added in pellet per $100 \mathrm{~g}$.) The metallization rate of pellets was $75.9 \%$ when no catalyst was added, and almost all catalysts can greatly increase the metallization rate of pellets. Among them, borax has the best catalytic effect, and the metallization rate can be reached $92.1 \%$. Besides, it can be seen from Figure 2 that the boron-based catalyst improves the metallization rate of the pellets more than the calciumbased catalyst.

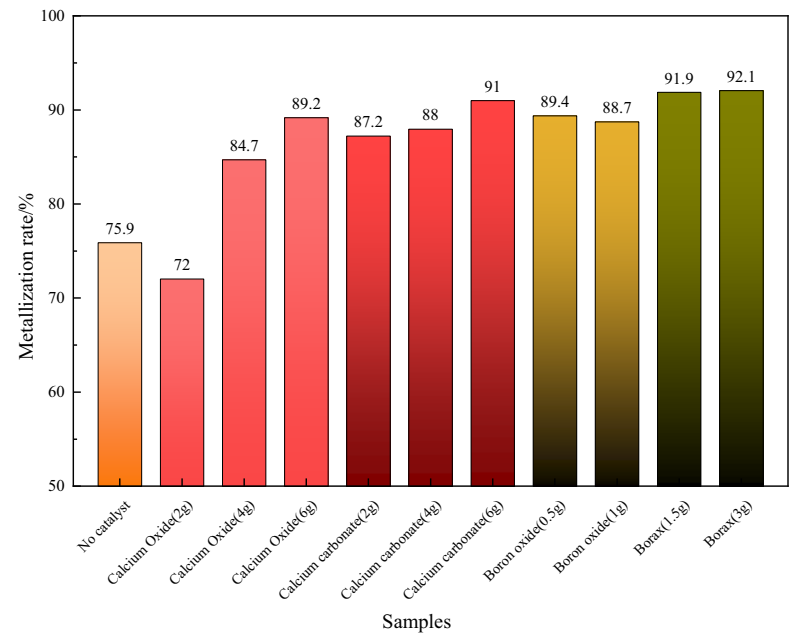

Figure 2. Effect of catalyst on the metallization rate of VTM pellets.

\subsection{Effect of catalyst on total tail gas composition and $\mathrm{CO}$ utilization rate}

In order to further analyze the difference between the two types of catalysts, the pellets with no catalyst, add $4 \mathrm{~g}$ calcium oxide, add $4 \mathrm{~g}$ calcium carbonate, add $0.5 \mathrm{~g}$ boron oxide and add $1.5 \mathrm{~g}$ borax were selected for comparative analysis. The total gas volume and main components of the tail gas during the reduction process of these pellets were calculated, and the results are shown in Figure 3. As can be seen from Figure 3, the pellets using catalysts all produce more tail gas compare to the no catalyst one. It is worth noting that, excluding hydrogen, calcium-based catalysts will produce more $\mathrm{COx}$ emissions than boronbased catalysts.

Figure 4 shows the effect of the catalyst on the $\mathrm{CO}$ utilization rate of pellet exhaust gas. It can be seen from the figure that without any catalyst, the $\mathrm{CO}$ utilization rate of the pellet tail gas is $28.7 \%$, while when calcium oxide and boron-based catalysts are added, the $\mathrm{CO}$ utilization rate decreases. But when calcium carbonate is added, the exhaust $\mathrm{CO}$ utilization rate increases to $30.4 \%$. This is mainly because calcium carbonate can be decomposed into calcium oxide and carbon dioxide under hightemperature conditions, thus increasing the $\mathrm{CO}$ utilization rate.

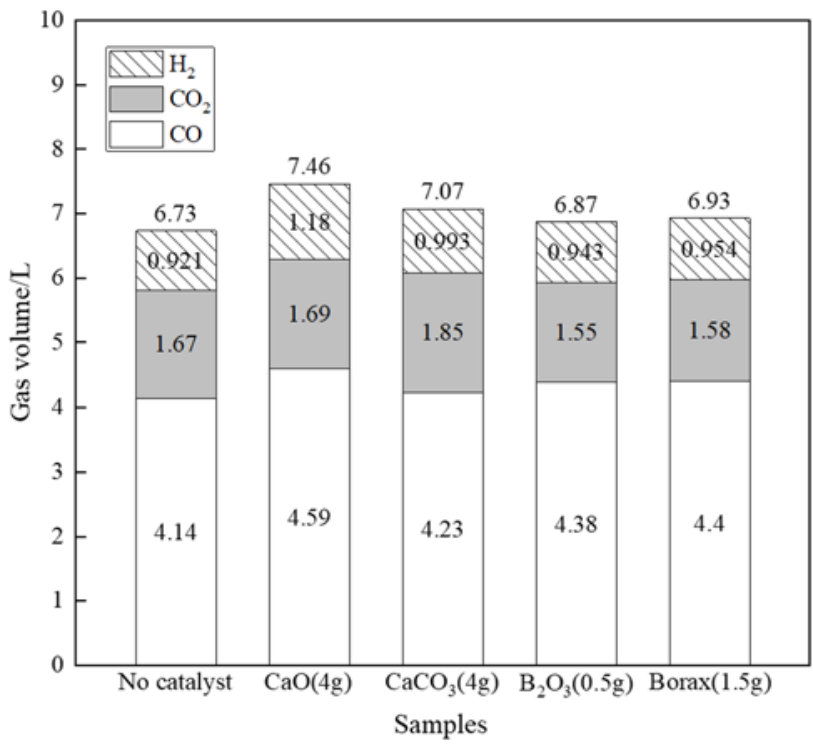

Figure 3. Effect of catalyst on the total tail gas composition of the pellets.

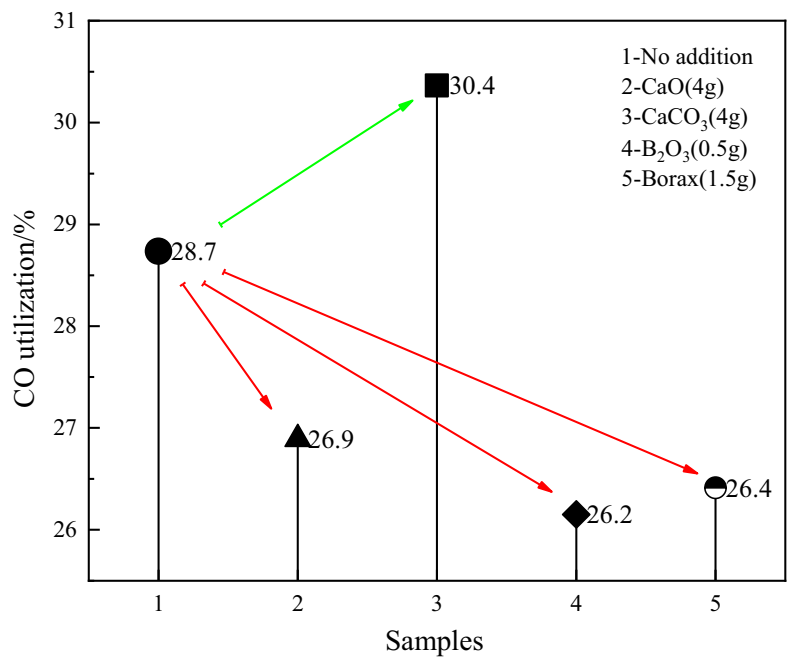

Figure 4. Effect of catalyst on $\mathrm{CO}$ utilization rate of the pellet reduction process. 


\subsection{Effect of catalyst on the change of tail gas composition during pellet reduction}

Figures 5, 6 and 7 are the change curves of $\mathrm{CO}, \mathrm{CO}_{2}$ and $\mathrm{H}_{2}$ in the pellet reduction process respectively when different catalysts are added. It can be seen from Figure 5 that there is a clear difference between the calcium-based catalyst and the boron-based catalyst for the change in the volume fraction of $\mathrm{CO}$ in the gas. Among them, under the effect of the boron-based catalyst, the volume fraction of $\mathrm{CO}$ is approximately the same as under the condition of no catalyst. It can be seen from the detail with the enlarged scale that the use of a boron-based catalyst can slightly increase the volume fraction of $\mathrm{CO}$. It can be inferred from this that the catalytic reduction of the vanadium-titanium magnetite carbon-containing pellets by the boron-based catalyst mainly promotes the reduction of iron oxide by $\mathrm{CO}$, rather than the gasification reaction of carbon. This phenomenon also confirmed the relevant literature[16]. Considered the carbothermal reduction process, the boronbased catalyst is easy to melt, and $\mathrm{B}^{3+}$ diffuses into the lattice of the titanium-iron compound, resulting in a decrease in binding energy and an increase in lattice parameters. At the same time, the boron catalyst also corrodes the surface of the iron ore, which increases the contact area between the reducing agent $\mathrm{CO}$ and the vanadium-titanium magnetite, thereby promoting the reduction. However, under the condition of $1000^{\circ} \mathrm{C}$, the gasification rate of $\mathrm{C}$ is very fast, so the volume fraction of CO hardly changes.

Unlike boron-based catalysts, the $\mathrm{CO}$ volume fraction changes a lot when calcium-based catalysts are used. It can be seen from Figure 5 that the volume fraction of $\mathrm{CO}$ increases significantly when calcium-based catalysts are added. This shows that the add calcium-based catalysts are beneficial to the gasification reaction of carbon, thereby promoting the reduction of vanadium-titanium magnetite. S. Mishra[17] has found that $\mathrm{CaO}$ can increase the porosity of carbon-containing pellets, improve the heat and mass transfer conditions inside the pellets, and strengthen the reduction effect. $\mathrm{CaCO}_{3}$ can decompose to produce $\mathrm{CO}_{2}$ and $\mathrm{CaO}$ after $851{ }^{\circ} \mathrm{C}$, which promotes the gasification reaction of carbon and produces more $\mathrm{CO}$. At the same time, the generated $\mathrm{CaO}$ can also strengthen the reduction effect. Therefore, the catalytic reduction effect of calcium carbonate is better than that of calcium oxide, and the utilization rate of $\mathrm{CO}$ is also higher. This can also be seen in Figure 6. The catalytic effect of $\mathrm{CaO}$ is embodied in promoting the reduction process in advance, but at low temperatures, the gasification reaction rate of carbon is slow, which makes the $\mathrm{CO}_{2}$ produced by the reduction accumulate. Calcium carbonate starts to decompose at $851^{\circ} \mathrm{C}$ to produce more $\mathrm{CO}_{2}$, and at this temperature, the gasification reaction of carbon is strengthened, thus can producing more $\mathrm{CO}$.

It can be seen from Figure 7 that the addition of $\mathrm{CaO}$ can improve the heat and mass transfer conditions, leading to the early escape of $\mathrm{H}_{2}$ in the coal and reducing the utilization rate of $\mathrm{H}_{2}$. This may be one of the reasons why the catalytic effect of $\mathrm{CaO}$ is worse than other catalysts. It can also be seen from Figure 3 that when $\mathrm{CaO}$ is added, the volume of $\mathrm{H}_{2}$ in the tail gas is the largest one.

In summary, the boron-based catalyst has a better catalytic reduction effect than the calcium-based catalyst, but the use of $\mathrm{CaCO}_{3}$ can greatly improve the $\mathrm{CO}$ utilization rate. Considering that the catalytic effect of $\mathrm{CaCO}_{3}$ is better than $\mathrm{CaO}$, meanwhile, $\mathrm{CaCO}_{3}$ can decompose to form $\mathrm{CaO}$ at high temperatures, while $\mathrm{CaO}$ is an important flux in the smelting process. Therefore, the ironmaking process can absorb $\mathrm{CO}_{2}$ in the tail gas to produce calcium carbonate through $\mathrm{CaO}$, which can reduce part of the $\mathrm{CO}_{2}$ emissions, and at the same time improve the reduction efficiency and $\mathrm{CO}$ utilization rate, and achieve the purpose of low carbon smelting. In the next stage, our group will calculate the material balance and energy consumption of this idea, and verify the feasibility of this method through experiments.

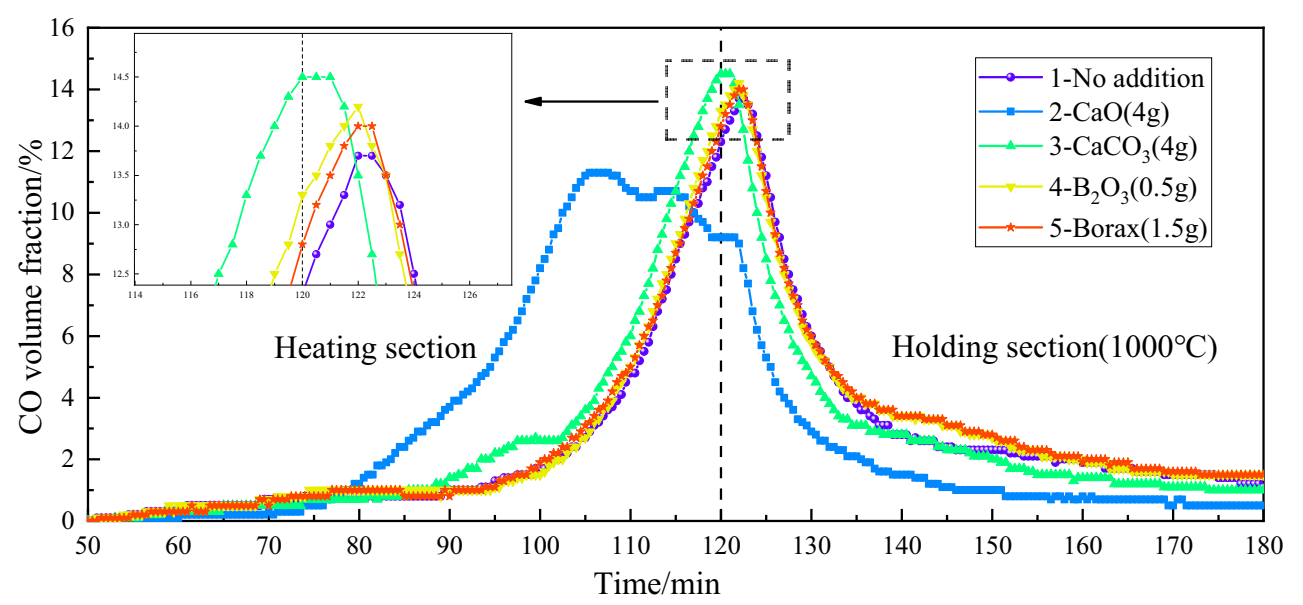

Figure 5. Effect of catalysts on $\mathrm{CO}$ volume fraction in tail gas. 


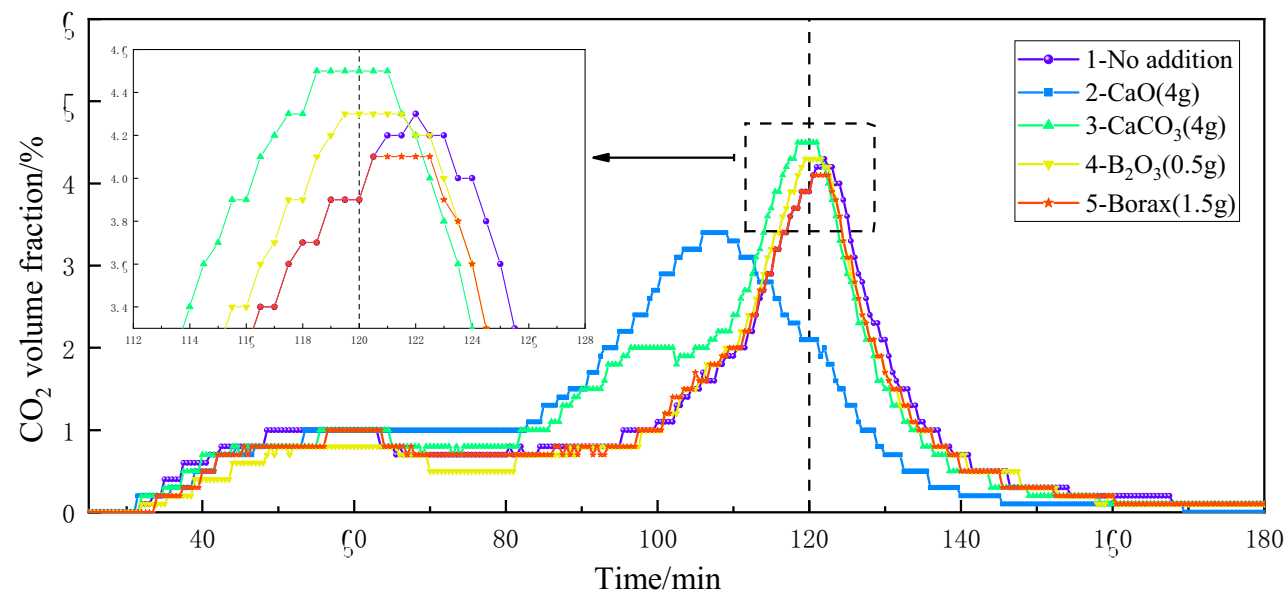

Figure 6. Effect of catalysts on the volume fraction of $\mathrm{CO}_{2}$ in tail gas.

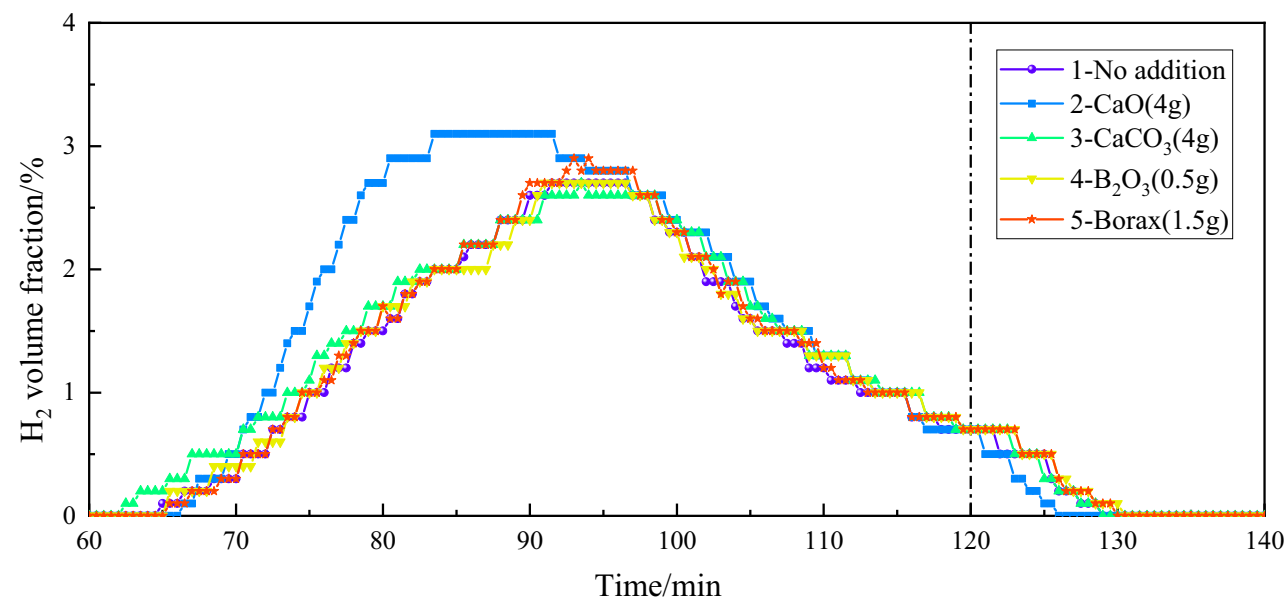

Figure 7. Effect of catalysts on the volume fraction of $\mathrm{H}_{2}$ in tail gas.

\section{Conclusions}

(1) Both calcium-based catalysts and boron-based catalysts can enhance the reduction of vanadiumtitanium magnetite carbon-containing pellets, and boron-based catalysts have better catalytic effects. In the case of adding $3 \mathrm{~g}$ of borax, the metallization rate of pellets can be increased from $75.9 \%$ to $92.1 \%$.

(2) Comparing the total volume of the tail gas and the composition, the addition of $\mathrm{CaO}$ will produce more gas emission and carbon oxide emission. The $\mathrm{CO}$ utilization rate of the pellet tail gas with $\mathrm{CaCO}_{3}$ is the highest, mainly due to the decomposition at high temperature to produce $\mathrm{CO}_{2}$, which makes full use of the characteristics of carbon-containing pellets and promotes the gasification reaction of carbon.

(3) Through the analysis of the changes in the volume fraction of each gas in the reduction process, it can be seen that the catalytic process principles of the boron-based catalyst and the calcium-based catalyst are significantly different. Boron-based catalysts do not affect the changes of the various gas components in the tail gas during the reduction process, while the calcium-based catalysts have a greater impact on the tail gas components.

\section{Acknowledgement}

This research was supported by the National Key Research Development Program of China, grant number 2017YFB0603800.

\section{References}

1. R. Y. An, B. Y. Yu, R. Li, Y. M. Wei, Appl. Energy 226, 862-880 (2018).

2. Y. Yang, M. J. Hu, Y. Li, L. Y. Wen, M. L. Hu, L. W. Hu, J Clean Prod 268, (2020).

3. J. Y. Song, Z. Y. Jiang, C. Bao, A. J. Xu, Metals 9, 15 (2019).

4. J. J. Gao, L. K. Hong, J. Zhang, Y. H. Qi, D. L. Yan, Iron Steel Vanadium Titanium 39, 8-13 (2018).

5. J. J. Gao, X. Y. Wan, Y. H. Qi, F Wang, Journal of Iron and Steel Research, 91-96 (2018).

6. B. Wang, X. Y. Ding, T. H. Ju, X. F. Zhang, G. J. Cheng, Metals 11, (2021).

7. L. Y. Shi, Y. L. Zhen, D. S. Chen, L. N. Wang, T. Qi, ISIJ Int. 58, 627-632 (2018).

8. T. Hu, X. W. Lu, C. G. Bai, G. B. Qiu, Int. J. Miner. Metall. Mater. 21, 131-137 (2014). 
9. H. J. Ge, W. T. Zhou, Y. L. Guo, X. Y. Zhao, Sintering and Pelletizing, 39, 27-31+46 (2014).

10. A. A. El-Tawil, H. M. Ahmed, A. A. El-Geassy, B. Bo, in Conference of Metallurgists. (2015).

11. L. H. Zhang, S. T. Yang, W. D. Tang, X. X. Xue, Minerals 9, 14 (2019).

12. Z. G. Liu, M. S. Chu, H. T. Wang, W. Zhao, X. X. Xue, Int. J. Miner. Metall. Mater. 23, 25-32 (2016).

13. Y. H. Lin, Y. C. Wen, W. G. Fu, J. T. Rao, Metall. Res. Technol. 113, 8 (2016).

14. H. Liu, K. Zhang, Q. F. Ling, Y. L. Qin, J. Chem. 2020, 9 (2020).

15. Y. Q. Zhao, T. C. Sun, Z. Y. Li, C. Y. Xu, S. C. Wu, Chinese Journal of Engineering, 42, 838-845 (2020).

16. X. D. Xing, S. Wang, Z. G. Pang, Q. L. Zhang, Metall. Res. Technol. 116, 9 (2019).

17. S. Mishra, G. G. Roy, Ironmak. Steelmak. 45, 426433 (2018). 